\title{
Implicancias normativas del rule of law y su relación con la exigencia de objetividad*
}

\author{
Regulatory Implications of the Rule of \\ Law and its Relationship with Objectivity
}

\author{
Consequências regulatórias \\ do rule of law e sua relação com \\ a exigência de objetividade
}

Matías Pedernera Allende ${ }^{* *}$
* Un agradecimiento a los profesores Juan Cianciardo, Pilar Zambrano y Jordi Ferrer Beltrán por algunos valiosos comentarios a una versión anterior de este trabajo, que han sido tenidos en cuenta en este artículo, y que fue presentado como parte de la tesis final del Master in Global Rule of Law and Constitutional Democracy de la Universi- dad de Génova y la Universidad de Girona.
** https://orcid.org/0000-0002-8716-7860. Universidad Nacional de Córdoba, Argentina. mpedernera.allende@mi.unc.edu.ar

Recibido: 30/04/2020. Envío a pares: 09/05/2020 Aprobado por pares: 08/06/2020. Aceptado: 09/06/2020

DOI: $10.5294 /$ dika.2020.29.1.9 


\section{Resumen}

El rule of law es una de las nociones fundamentales de la práctica jurídica contemporánea. Uno de los posibles interrogantes relativos a la vigencia de un ideal normativo como el rule of law tiene que ver con cuáles son las implicancias que se siguen para determinado sistema jurídico político. En otras palabras, qué estados de cosas deberían garantizarse en un Estado para afirmar que el rule of law se encuentra vigente. Ante ese interrogante, surge una pregunta conexa e implícita que indaga acerca de la relevancia y la conexidad de la objetividad en el campo jurídico, frente al ideal del rule of law. En este trabajo se explicará qué supone afirmar que el rule of law es una exigencia de naturaleza jurídica, política y ética. Asimismo, se sistematizarán las implicancias normativas del rule of law para determinado sistema jurídico político. Seguidamente, y a partir de lo anterior, se procurará identificar la conexión existente entre el rule of law y cierta idea de objetividad en el campo del derecho.

\section{Palabras clave}

Rule of Law; estado de derecho; objetividad; previsibilidad; división de poderes; dignidad humana. 


\section{Abstract}

The rule of law is a fundamental notion of contemporary legal practice. A pertinent question regarding the validity of a regulatory ideal, such as the rule of law, has to do with its implications for a particular political-legal system: What state of affairs should a State guarantee to affirm that the rule of law is in force? This raises a related implicit issue concerning the relevance and connectedness of law's objectivity to the ideal of the rule of law. This paper intends to explain what it means to affirm that the rule of law is a requirement of a legal, political, and ethical nature. It systematizes the regulatory implications of the rule of law for a given political-legal system. Accordingly, it attempts to identify the link between the rule of law and the idea of objectivity.

\section{Keywords}

Rule of Law; objectivity; foreseeability; separation of powers; human dignity. 


\section{Resumo}

O rule of law é uma das noções fundamentais da prática jurídica contemporânea. Uma das possíveis questões relativas à vigência de um ideal regulatório como o rule of law se refere a quais são as consequências para determinado sistema jurídico político. Em outras palavras, quais estados de coisas deveriam ser garantidos em um Estado para afirmar que o rule of law se encontra válido. Diante disso, surge uma pergunta conexa e implícita sobre a relevância e a conexão da objetividade no campo jurídico ante o ideal de rule of law. Neste trabalho se pretende explicar o que supõe afirmar que o rule of law se trata de uma exigência de natureza jurídica, política e ética. Além disso, são sistematizadas as consequências regulatórias do rule of law para determinado sistema jurídico político. Em seguida, e a partir disso, pretende-se identificar a conexão existente entre o rule of law e certa ideia de subjetividade no campo do Direito.

\section{Palavras-chave}

Rule of Law; Estado de Direito; objetividade; previsibilidade; separação de poderes; dignidade humana. 
Sumario: Introducción. 1. El rule of law como ideal jurídico, político y ético. 1.1. El Rule of Law como ideal jurídico. 1.2. El Rule of Law como ideal político. 1.3. El Rule of Law como ideal ético. 2. Las implicancias normativas del rule of law. 2.1. Eficiencia decisoria. 2.2. Distribución y control del poder decisorio. 2.3 Previsibilidad. 3. La objetividad como exigencia inherente al rule of law. Conclusión. Bibliografía.

\section{Introducción}

La idea de rule of law ${ }^{1}$ es una de las nociones fundamentales de la práctica jurídica contemporánea. La determinación de su alcance y contenido no resulta pacífica, sin embargo, una de las caracterizaciones más difundidas entre los teóricos del derecho es la que identifica al rule of law con la idea de legalidad formal. Se trata de un conjunto de exigencias formales que los sistemas de normas deben cumplir para asegurar su eficacia.

Más allá de las exigencias concretas del rule of law, su finalidad tiende a asegurar la guía de la conducta humana por medio de reglas. Indudablemente, esto no puede lograrse si dichas normas no son inteligibles. Los agentes destinatarios de las reglas no podrían cumplir algo que no conocen. Asimismo -aunque con menos acuerdo-, se ha afirmado que la idea de rule of law cumple una función moral al contribuir al resguardo de la dignidad humana, en el sentido de tratar a los ciudadanos como agentes capaces de planificar su futuro. Además de la inteligibilidad, el cumplimiento de las exigencias del rule of law asegura previsibilidad y permite a los agentes actuar con libertad.

Uno de los posibles interrogantes relativos a la vigencia de un ideal normativo como el rule of law tiene que ver con cuáles son las implicancias que se siguen para determinado sistema jurídico político. En otras palabras, qué estados de cosas deberían garantizarse en un Estado para afirmar que el rule of law se encuentra vigente. Ante este interrogante surge una pregunta conexa e implícita que indaga acerca de la relevancia y la conexidad de la objetividad en el campo jurídico frente al ideal del rule of law.

En este trabajo se explicará, en primer lugar, qué supone afirmar que el rule of law es una exigencia de naturaleza jurídica, política y ética. En segundo lugar, siguiendo la propuesta del profesor italiano Bruno Celano, se sistematizarán las implicancias normativas del rule of law para determinado sistema jurídico

1 Se utilizará el término rule of law, sin perjuicio de las posibles semejanzas que este presenta respecto del término Estado de derecho, propio de la tradición jurídica continental. La idea de rule of law se desarrolló en el marco de la tradición anglosajona del common law, en la cual el derecho formaba parte de las costumbres nacionales y era algo anterior al Estado. Precisamente por eso, podía servirle de límite. En cambio, la noción de Estado de derecho se desarrolló en el contexto de la tradición continental, en la cual el Estado poseía el monopolio de la creación del derecho. Se trata de lo que algunos autores han denominado rule by law, es decir que, el derecho constituía un medio de gobierno, más que un límite extrínseco (Pedro Rivas, "Política, poder y derecho. La noción hobbesiana de soberanía en la encrucijada de sentido de lo jurídico y lo político", en Anuario Filosófico 51 (1) (2018), pp. 17 y ss.). 
político. En tercer lugar, y a partir de lo anterior, se procurará identificar la conexión existente entre el rule of law y cierta idea de objetividad en el campo del derecho.

\section{El rule of law como ideal jurídico, político y ético}

Existen diversas posiciones acerca de qué debe entenderse por rule of law y cuál es su alcance. Estas varían desde propuestas estrechas que consideran que se satisface dicho ideal cuando el Gobierno desarrolla su acción oficial por medio del derecho (rule by law), hasta otro extremo más robusto donde se hallan las posiciones que postulan que un sistema que satisface el ideal de rule of law presenta determinadas cualidades formales $\mathrm{y}$, además, promueve derechos individuales y sociales, y asume los principios democráticos. ${ }^{2}$

En lo que respecta a este trabajo, se tomará partido por una de las posibles posiciones, de la gama de las posturas estrechas. Se trata de una postura que concibe al rule of law como un ideal que comprende determinadas exigencias formales respecto del derecho: generalidad, prospectividad, publicidad, estabilidad, claridad, consistencia y posibilidad en el cumplimiento; y determinadas exigencias institucionales y procedimentales (por ejemplo, que la emisión de normas individuales debe partir de normas generales, la independencia judicial o el acceso a la justicia). ${ }^{3}$

Esta consideración formal o instrumental del rule of law se halla vinculada con, al menos, un objetivo: la guía de la conducta humana. ${ }^{4}$ Por ello, se ha afirmado que las exigencias del rule of law constituyen reglas de segundo orden que permiten verificar que reglas de primer orden cumplan ese objetivo, ${ }^{5}$ es decir, las normas jurídicas positivas. Ello supone que el logro del objetivo de guiar la conducta adquiere protagonismo por sobre otros posibles fines sustantivos que se busquen por medio de la técnica jurídica. ${ }^{6}$

De acuerdo con otro de los argumentos, para mantener la separación entre reglas procedimentales (rule of law) y reglas sustantivas de primer orden, no sería necesario adherir a determinada filosofía política acerca de lo que implica una sociedad buena o de un buen derecho para adherir al rule of law. ${ }^{7}$ El ideal

Brian Tamanaha, On the Rule of Law. History, Politics, Theory, Cambridge, Cambridge University Press, 2004, pp. 91 y ss.

3 Bruno Celano, "Publicity and the Rule of Law", en Leslie Green y Brian Leiter (eds.), Oxford Studies in Philosophy of Law, vol. 2, Oxford, Oxford University Press, 2013, p. 130.

Ibid., p. 133.

Robert Summers, "The principles of the Rule of Law", en Notre Dame Law Review, 74 (1999), p. 1709.

6 De todos modos, como también se ha dicho, el rule of law no es simplemente un instrumento técnico, sino que presenta un valor sustantivo en sí mismo dado que lo que busca es la guía de la conducta de personas humanas.

7 Paul Craig, "Formal and substantive conceptions of the rule of law: An analytical framework", en Public Law, 3 (1997), p. 467. 
del rule of law, en cuanto exigencia de segundo orden, podría compatibilizarse con orientaciones fundamentales de diversa índole. Para quienes sostienen la separación entre directivas procedimentales y sustantivas, si se unificara al rule of law con exigencias sustantivas en un híbrido, el debate público no solo giraría en torno a los objetivos esenciales que la sociedad debe perseguir, sino también a cómo debe gobernarse la conducta de los ciudadanos. ${ }^{8}$

Desde esta perspectiva formal o instrumental, las exigencias del rule of law proyectan sus efectos en, al menos, tres direcciones: jurídica, ética y política.

\subsection{El rule of law como ideal jurídico}

En cuanto ideal jurídico, el objetivo nuclear del rule of law se encuentra vinculado con la guía de la conducta. La satisfacción de determinados requerimientos formales tiene que ver con este objetivo relacionado con la idea de eficacia, aun cuando suponga algunas implicancias éticas y políticas.

De este modo, si -en cuanto instrumento de gobierno- se quiere que un sistema jurídico sea obedecido, uno de los requisitos para ello es la publicidad de las prescripciones. Si los ciudadanos no saben qué debe hacerse, obviamente no podrán acatar reglas en ningún sentido. En esta línea se inscriben exigencias del rule of law como las de promulgación y claridad.

La publicidad de las prescripciones, en un sentido preciso, comprende un "conocimiento compartido". Es decir, no se trata de que las personas sujetas al derecho sepan colectivamente a qué se refieren las normas, sino que es preciso que cada individuo en particular conozca su contenido. De ese modo, si "a sabe que $p$ " y "b sabe que $p$ ", y "a sabe que b sabe que $p$ " (y viceversa), tanto $a$ como $b$ podrán planificar sus conductas en relación con el Gobierno y en relación con el resto de los agentes sujetos al sistema jurídico. ${ }^{9}$ De este modo, la publicidad no solo compromete la eficacia del sistema jurídico, sino también a tratar a las personas qua agentes.

Por otra parte, los principios formales del rule of law también contienen directivas en cuanto a la orientación temporal de las prescripciones. De este modo, las órdenes de gobierno, si han de ser obedecidas, no deben ser retroactivas y deben mantenerse relativamente estables en el tiempo. En relación con la exigencia de prospectividad, si lo que se busca lograr mediante la emisión de una prescripción es que alguien haga o deje de hacer algo, ciertamente no tendría sentido mandar hoy a hacer algo ayer. ${ }^{10}$

8 Summers, "The principles of the Rule of Law", op. cit., pp. 1710-1711.

10 Francisco Laporta, El imperio de la ley, Madrid, Trotta, 2007, p. 88. 
Por su parte, la exigencia de estabilidad relativa supone un balance entre constancia y adaptabilidad. Si las prescripciones fuesen alteradas con celeridad en cortos periodos de tiempo, las personas no tendrían la oportunidad de asumirlas en su razonamiento práctico. Esto afectaría el funcionamiento eficaz del sistema. ${ }^{11}$ Tanto la prospectividad como la estabilidad repercuten en la planificación por parte de los agentes destinatarios de las prescripciones.

Finalmente, los tres restantes principios formales del rule of law se relacionan directamente con los sujetos a quienes se dirigen las prescripciones. A su vez, estos presentan orientaciones diversas. Por un lado, la generalidad de las normas tiene que ver con la formulación no particularizada de estas. Las prescripciones se dirigen a una clase de sujetos y a ninguno en particular, ${ }^{12}$ salvo excepciones. Esto constituye una garantía de igualdad para las personas. Desde el punto de vista de la eficacia, también es una ventaja puesto que sería improbable que un sistema de gobierno pudiese funcionar mediante permanentes órdenes particulares.

Desde otra perspectiva, las prescripciones deben ser posibles de cumplir y, a su vez, deben ser coherentes. Respecto de lo primero, se trata de una posibilidad lógica, conceptual y humana. Una prescripción que ordena cosas imposibles es un abuso de la institución de prescribir que procura objetivos distintos a la guía de la conducta. ${ }^{13}$ Por otra parte, la exigencia de coherencia supone que el sistema jurídico no debe reclamar conductas cuyo cumplimiento suponga una contradicción con otras prescripciones del propio sistema. ${ }^{14}$ Se trata de un caso de posibilidad de cumplimiento, pero de tipo jurídico.

\subsection{El rule of law como ideal político}

En cuanto ideal político, el rule of law constituye un modo especial de ejercicio del poder. Ciertamente, pueden existir diversas maneras de guiar la conducta. Sin embargo, una cualidad sobresaliente del poder ejercitado bajo las exigencias del rule of law es la de ser no manipulativo. A diferencia de otros modos de influir sobre la conducta humana, como las amenazas o la propaganda, las prescripciones formuladas desde este esquema precisan que los destinatarios conozcan su contenido a fin de que puedan adherir voluntariamente a ellas. El rule of law en cuanto modo de ejercicio del poder, no presupone el cumplimiento involuntario de las prescripciones. ${ }^{15}$ 
Se trata de un modo racional de ejercicio del poder. Esa racionalidad no solo tiene un carácter instrumental en cuanto considera el objetivo por lograr -la guía de la conducta-, sino que, a su vez, la racionalidad tiene que ver con los destinatarios de las prescripciones. La configuración de las reglas es racional, porque los destinatarios son racionales. ${ }^{16}$ Precisamente por esto, prescripciones incoherentes, imposibles de cumplir, inestables, etc., son irracionales. Porque los sujetos no pueden comprenderlas, no pueden deliberar respecto de ellas, no pueden planificar y, en consecuencia -mucho menos- obedecer.

De lo anterior se sigue, además, que un modo de ejercicio de poder no manipulativo, que presupone el conocimiento y la adhesión de los destinatarios es, asimismo, no paternalista. ${ }^{17}$ Esto, en el sentido de que el sistema los trata infantilmente, altomar determinaciones por ellos y prescindir de su capacidad de tomar decisiones, deliberar y planificar. Por el contrario, un sistema adherido al rule of law, presupone que los destinatarios conocen las reglas, las sopesan, toman decisiones respecto de ellas y prevén las consecuencias.

\subsection{El rule of law como ideal ético}

En cuanto ideal ético, si bien el rule of law -tal como aquí ha sido presentadoofrece un carácter instrumental y, por tanto, compatible con ciertas formas de injusticia, su configuración presenta cualidades moralmente valiosas. Precisamente por requerir el conocimiento y el consentimiento de los destinatarios, el rule of law guarda deferencia para con los individuos como agentes racionales. En este sentido, promueve su dignidad en cuanto resguarda las condiciones para la previsión de las consecuencias de las propias acciones y la planificación del futuro.

Diversos autores han enfatizado la contribución del rule of law a la dignidad humana. Paradigmáticamente, Lon Fuller ha afirmado que

... toda desviación de los principios de la moral interna del derecho [de los principios del rule of law] es una afrenta a la dignidad del hombre como factor responsable. Juzgar sus acciones por leyes no publicadas o retroactivas, $u$ ordenarle que cometa un acto que es imposible, es demostrar nuestro desprecio por sus facultades de libre determinación. ${ }^{18}$

Por su parte, Raz ha afirmado que "la observancia del [rule of law] es necesaria si el derecho debe respetar la dignidad humana", y que "el deliberado desprecio del [rule of law] viola la dignidad humana". ${ }^{19}$

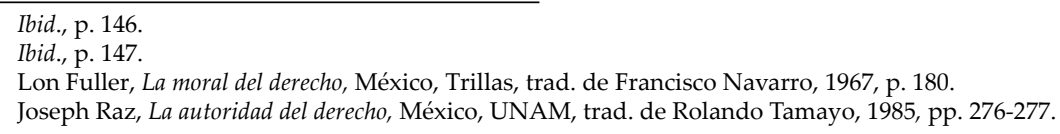


Dada esta relación entre los principios del rule of law y la dignidad humana, se ha afirmado que el primero constituye una condición necesaria de respeto a la segunda $-y$ más precisamente, a la noción de autonomía personal,$-^{20}$ aunque no es condición suficiente. Desde esta perspectiva, los principios del rule of law, en cuanto exigencias normativas e institucionales del ejercicio del poder político, no se justifican en virtud de otras normas jurídicas, sino en principios metajurídicos, entre los cuales se encuentra la dignidad humana. Por ello, "la idea de autonomía personal [como expresión de la noción de dignidad] va a cumplir aquí su doble función de postulado de justificación y de criterio de orientación" ${ }^{21}$ del rule of law.

En conexión con lo anterior, el rule of law adquiere cierto valor ético por su contribución a la libertad humana. En efecto, no solo garantiza un rango de opciones respecto del cual los agentes deliberarán, sino que, además, garantiza una cierta independencia de la voluntad de otros. Es decir, que como medio de ejercicio del poder, no reemplaza la voluntad personal ni presupone cumplimientos involuntarios. De este modo, satisface la libertad en el sentido de "no interferencia". ${ }^{22}$

\section{Las implicancias normativas del rule of law}

En cuanto ideal jurídico, político y ético, el rule of law supone una serie de implicancias normativas que se encontrarían ausentes cuando el poder estatal no fuese ejercido de modo racional, público o no paternalista. En el desarrollo precedente, se han identificado determinadas exigencias e implicancias que el rule of law presupone. En lo que sigue, se precisarán al menos tres consecuencias normativas que se desprenden de la satisfacción de un ideal como el rule of law: eficiencia decisoria, distribución del poder decisorio y previsibilidad. ${ }^{23}$

\subsection{Eficiencia decisoria}

La vigencia de un ideal como el rule of law es la de un esquema jurídico y político donde las reglas ocupan un lugar central. Como se ha dicho, el objetivo de este esquema es la guía de la conducta humana, y ello se logra a través de normas generales y abstractas que satisfacen determinados requisitos forma-

20 Laporta, El imperio de la ley, op. cit., p. 34; Bruno Celano, “Rule of Law y Particularismo Ético”, en Pau Luque (ed.), Particularismo. Ensayos de filosofía del derecho y filosofía moral, Madrid, Marcial Pons, 2015, p. 177.

21 Laporta, El imperio de la ley, op. cit., p. 18. Se introduce la aclaración de que la autonomía constituye cierta "expresión" de la dignidad, en el sentido de que no la agota. Ello por cuanto se asume que todos los individuos pertenecientes a la especie humana, independientemente de su efectiva capacidad para decidir autónomamente, son seres dignos (Juan Cianciardo, "Derechos humanos", en Claudia Vanney et al. (eds.), Diccionario Interdisciplinar Austral (2018), en http://dia.austral.edu.ar/Derechos_humanos, p. 8, fecha de consulta: 7 de abril de 2020).

22 Nigel Simmonds, "Law as a moral idea", en University of Toronto Law Journal, 55 (2005), p. 85 y ss.

23 El esquema que se seguirá ha sido propuesto y desarrollado por Celano, "Rule of Law y particularismo ético", op. cit., pp. 151-186. 
les. El hecho de que se tome a las reglas como instrumentos para gobernar la conducta contrasta con otras alternativas para lograr ese objetivo, como la exhortación, la propaganda o la costumbre. ${ }^{24}$ Otro grupo de alternativas tiene que ver con la adopción de decisiones particulares y concretas en cada caso que se requiera.

Frente a ese contraste, las reglas sirven para simplificar las decisiones (decisiones públicas, en el caso). Al basarse en generalizaciones, hacen que no sea necesario efectuar un balance de razones cada vez que debe tomarse una decisión. De este modo, permiten economizar recursos decisorios escasos ${ }^{25} \mathrm{y}$ solucionar problemas de coordinación. Así, frente opciones igualmente razonables, se hace necesario contar con un criterio compartido para la guía de la conducta. Desde este punto de vista, el derecho en general, y las reglas jurídicas en particular, cumplen un papel determinativo frente a, por ejemplo, las normas morales. ${ }^{26}$

Otro modo de economizar recursos decisorios se da respecto de las limitaciones de las capacidades de las personas. De esta manera, las reglas tendrían la posibilidad de mitigar ciertas limitaciones cognitivas. En efecto, la cognición humana adolece de ciertos sesgos que conducen a cometer determinados errores sistemáticos. ${ }^{27} \mathrm{El}$ recurso a las reglas, mediante la adopción genérica de soluciones no afectadas por dichos sesgos, puede coadyuvar a mantenerlos bajo control. ${ }^{28}$ Por otro lado, ocurre algo similar con los llamados sesgos emotivos. La adopción de decisiones mediante reglas podría ser una prevención frente a elecciones apresuradas o excesivamente apasionadas.

\subsection{Distribución y control del poder decisorio}

Como se señaló, las reglas contribuyen a la solución de los problemas de coordinación en el marco de una cierta convivencia entre las personas. En este contexto, el comportamiento humano se encuentra sujeto a alguna forma de gobierno. Desde esta perspectiva, las personas no son solo sujetos de decisión, sino también su objeto. La propia conducta es materia de decisión ajena y, evidentemente, alguien debe tomar las decisiones. En relación con ello, Celano ha identificado dos posibles problemas que apareja el poder decisorio: el de su distribución y el de su control. ${ }^{29}$

\footnotetext{
24 John Finnis, “Law as co-ordination”, Ratio Juris, 1 (1989), p. 102.

25 Celano, "Rule of Law y particularismo ético", op. cit., p. 162.

26 Juan Bautista Etcheverry, "La relevancia del derecho que remite a la moral", en Problema. Anuario de Filosofía y Teoría del Derecho, 4 (2010), pp. 231-233.

27 Por ejemplo: el "efecto de arrastre", la "heurística de la disponibilidad", o el "efecto del encuadre".

28 Celano, "Rule of Law y particularismo ético", op. cit., pp. 162-163. Celano aclara que las reglas pueden contribuir a controlar algunos de los sesgos cognitivos, aunque en algunos casos también pueden petrificar determinados errores provocados por ciertos sesgos. 
Dado que las decisiones que se tomen afectan la propia vida de los miembros de la comunidad, la "arquitectura" del poder decisorio debe diseñarse de modo satisfactorio para los propios afectados. En este contexto, la existencia de un "ambiente decisorio" en el que clases de decisiones se atribuyan a clases de decisores, es algo que puede ser logrado mediante reglas y, por tanto, promovido por un ideal como el rule of law. ${ }^{30}$

De este modo, "las reglas sustraen ciertas decisiones a la jurisdicción (es decir, a la competencia para juzgar, para tomar decisiones) de ciertos sujetos, reservándola para otros, y vinculando a los primeros a las decisiones de los segundos. Son instrumentos, por tanto, para la asignación de clases de decisiones a clases de decisores". ${ }^{31}$ Así, la selección de las propiedades relevantes contenidas en la regla quedará en manos de un grupo de decisores. La aplicación de esas propiedades a un caso concreto quedará en manos de otro.

Dicha sustracción de competencia en dos planos constituye un freno que, aunque no es definitivo, minimiza los riesgos de arbitrariedad.

Por un lado, la atribución a un decisor de la tarea de producir reglas que serán aplicadas por otros hace más difícil [...] tomar decisiones que privilegien, o perjudiquen, a individuos particulares. Por otro lado, la atribución a un decisor de la tarea de aplicar reglas preconstituidas convierte en controlables a las decisiones. ${ }^{32}$

De este modo, las reglas se erigen en estándares para evaluar la conformidad de las decisiones de quienes las aplican, respecto de las decisiones de quienes las diseñan.

En este sentido, se ha dicho que "adherir al imperio del derecho [...] siempre tiende a reducir la eficiencia para el mal de un gobierno malo, pues limita sistemáticamente la libertad de maniobra del gobierno". ${ }^{33}$ La distribución y el control del poder de decisión tienden a reducir el margen de quienes detentan el poder para tomar decisiones arbitrarias, aunque probablemente no agote dicha posibilidad. Este punto está vinculado con la posición estrecha de rule of law que aquí se ha asumido. Al ser el rule of law un ideal formal (aunque con cierto contenido sustantivo) no es capaz de prevenir todas las injusticias, y, por este motivo, no es condición suficiente para el resguardo de la dignidad humana. Sin embargo, sí es condición necesaria para ello, y en esa cualidad interviene la reducción de la arbitrariedad que dicho ideal apareja.

La limitación del poder público por medio de reglas constituye una importante condición para la promoción de la libertad de las personas. Ello, a partir de -al

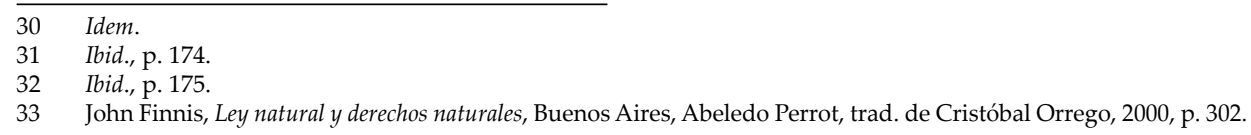


menos- dos sentidos. En primer lugar, quienes se hallan sujetos a reglas, y a la vez se encuentran frente a un decisor que debe adoptar un curso de acción sobre sus vidas, de algún modo están protegidos frente a este. ${ }^{34}$ Ello, por cuanto quien decide no debería obrar conforme a sus propios criterios o pareceres -en definitiva, a su propia voluntad-, sino conforme a reglas preestablecidas. Una decisión justificada, en este caso, es aquella que se sigue de las reglas y no de la voluntad de los decisores.

En segundo lugar, quienes viven en una comunidad política sujeta a los principios del rule of law también gozan de un cierto margen de libertad entendida como no dominación. Ello por cuanto, como se ha indicado precedentemente, los requerimientos formales del rule of law hacen que las reglas deban ser inteligibles a fin de que las personas puedan adherir voluntariamente a ellas. Tal esquema de gobierno no asume el cumplimiento involuntario o forzoso de las reglas. ${ }^{35}$ Desde esta perspectiva, puede afirmarse que el rule of law es condición para la libertad entendida como no dominación. ${ }^{36}$

\subsection{Previsibilidad}

Vinculado al apartado precedente, se ha afirmado que el rule of law constituye una condición necesaria para el respeto de la autonomía de aquellos que están sujetos a él, ${ }^{37}$ autonomía entendida como la capacidad para elaborar planes a largo plazo para la propia vida, y de valorar y decidir con base en principios formulados por uno mismo. ${ }^{38} \mathrm{~A}$ su vez, como se indicó, la noción de autonomía ha sido asociada a la idea de dignidad, la que -en palabras de Raz- "implica tratar a los humanos como personas capaces de planificar y diseñar su futuro". ${ }^{39}$

De este modo, se ha señalado que hay al menos dos sentidos en que no seguir los principios del rule of law afecta la autonomía: cuando el sistema jurídico conduce a incertidumbre, es decir, cuando la falta de previsibilidad obstaculiza la toma de decisiones; o cuando genera falsas expectativas, como cuando se dictan normas retroactivas. ${ }^{40}$ Tanto en el caso de la incertidumbre como en el de las falsas expectativas, el ejercicio del poder público interviene en la vida de las personas para truncar el diseño y la consecución de los propios planes de vida.

En sintonía con lo planteado en los apartados precedentes, la decisión basada en reglas tiende a asegurar la previsibilidad de las decisiones. ${ }^{41}$ En contraste

Celano, "Rule of Law y particularismo ético", op. cit., p. 176.

Ibid., p. 146 y ss.

Simmonds, "Law as a moral idea", op. cit., pp. 85 y ss.

Celano, "Rule of Law y particularismo ético", op. cit., p. 177.

Robert Nozick, Anarchy, State and Utopia, New York, Basic Books, 1974, p. 49.

Raz, La autoridad del derecho, op. cit., p. 276.

Ibid., p. 277.

Celano, "Rule of Law y particularismo ético", op. cit., p. 179. 
con decisiones ad hoc que dependan exclusivamente de la voluntad del decisor, la decisión basada en reglas tiene como antecedente a un conjunto de propiedades relevantes, que son conocidas por el agente a quien afectan de manera previa a su aplicación. En cambio, una decisión ad hoc es un método poco o nada previsible $y$, por tanto, no parece idóneo como mecanismo de toma de decisiones públicas en las que se afectan vidas ajenas.

Precisamente, a partir de ello se ha señalado que la idea de "certeza jurídica" tiene como ratio originaria a la posibilidad de planificar la propia existencia de un modo jurídicamente informado y consciente. La previsibilidad tiene sentido en cuanto contribuye al planteo y seguimiento de los propios objetivos y comprende, no solo la previsión del derecho efectivo, sino también ciertos elementos fácticos, ${ }^{42}$ como la idea de "conocimiento compartido": ${ }^{43}$ saber que el conciudadano sabe lo que dice el derecho.

La certeza jurídica como previsibilidad tiene que ver, entonces, con "una situación de hecho caracterizada por una posibilidad, más o menos difundida y extensa, de prever los hechos que acaecen en virtud del derecho, y que producen consecuencias en la vida de los individuos". ${ }^{44}$ En este sentido, el derecho -como hecho institucional que afecta la vida de las personas- debe funcionar como un mecanismo, es decir, debe funcionar de manera regular y previsible, lo que -por supuesto- incluye a las decisiones basadas en el derecho. ${ }^{45}$

Por otra parte, y en relación con el apartado anterior, se ha señalado que, junto a la previsibilidad de las consecuencias jurídicas de la acción, debe ponerse la posibilidad de control de las decisiones jurídicas. Dicha posibilidad consiste en "valorar preventivamente, o también en un momento sucesivo, la conformidad de las elecciones particulares a un criterio general preconstituido" ${ }^{46}$ En este sentido, una decisión pública será tanto más previsible cuanto más justificada se encuentre. ${ }^{47}$ La justificación, en este caso, alude a la conformidad de la decisión con las reglas preestablecidas. ${ }^{48}$

42 Gianmarco Gometz, La certeza jurídica como previsibilidad, Madrid, Marcial Pons, trad. de Diego Moreno Cruz y Diego Dei Vecchi, 2012, pp. 228-229.

43 Celano, "Publicity and the Rule of Law",", op. cit., p. 129 y ss.

44 Gometz, La certeza jurídica como previsibilidad, op. cit., p. 224.

45 Celano, "Rule of Law y particularismo ético", op. cit., p. 178.

46 Claudio Luzzati, L'interprete e il legislatore. Saggio sulla certezza del diritto, Milán, Giuffrè, 1999, pp. 274-275. En el ámbito regional europeo e interamericano de protección de los derechos humanos goza de creciente difusión la aplicación del llamado "test de previsibilidad". En el caso de la Corte Interamericana de Derechos Humanos, López Mendoza vs. Venezuela (Sentencia de 1 de septiembre de 2011. Serie C, núm. 233, par. 199 y ss.), el tribunal declaró responsable al Estado demandado por cuanto "la falta de un plazo cierto, previsible y razonable puede dar lugar a un ejercicio arbitrario de la discrecionalidad a través de sanciones aplicadas en un momento totalmente inesperado para la persona que ya fue declarada responsable previamente" (par. 205).

48 Si bien se ha señalado la distribución del poder decisorio entre quienes diseñan las reglas y toman las decisiones, los diseñadores de reglas, es decir, los legisladores, también deben justificar sus decisiones conforme a reglas previamente existentes, y jerárquicamente superiores como las normas constitucionales. 
Un sistema jurídico respecto del cual es posible prever consecuencias es un sistema deferente con la dignidad de las personas que se encuentran sujetas a sus prescripciones. En la medida en que estas pueden saber cuáles son las consecuencias que se siguen de sus conductas, por la vigencia de las reglas, y que pueden saberlo de antemano, entonces logran planificar sus vidas teniendo en consideración esa influencia. Por el contrario, un sistema con reglas cambiantes, oscuras, secretas, o que dependen de la pura subjetividad de un aplicador, difícilmente contribuye a la planificación de la propia vida y, por tanto, se encontrará lejos de promover la autonomía de las personas.

\section{La objetividad como exigencia inherente al rule of law}

Del desarrollo precedente es posible inferir una idea implícita en la noción de rule of law: el compromiso con este supone también un compromiso con cierta idea de objetividad. Es decir, en cuanto ideal normativo, el rule of law guarda afinidad con estándares que presentan cierta rigidez o autonomía respecto de quienes prescriben las directivas para la guía de la conducta humana, más que con actitudes decisoras ad hoc, mutables y sorpresivas. Sobre la noción de objetividad se han distinguido tres géneros en el campo jurídico, con sus diversas especies.

Uno de estos géneros, la objetividad en sentido ontológico, involucra tres especies: como independencia mental (mind independence), como determinación y como aplicación uniforme de las reglas. Entendida en sentido epistémico, la objetividad se concreta en discernimiento transindividual e imparcialidad. Finalmente, en sentido semántico, la objetividad se concreta en una cierta aptitud para la verdad. ${ }^{49}$

Kramer ha propuesto que el compromiso con una objetividad jurídica traza la diferencia entre el gobierno del derecho (rule of law) y el gobierno de los hombres, en el sentido de gobierno de la mera voluntad humana. ${ }^{50}$ En atención a los fines de este trabajo, no se desarrollará esta tesis de una manera exhaustiva. En cambio, se considerará a la objetividad desde un punto de vista "ontológico", según las palabras del autor referido.

El compromiso con el ideal de rule of law supone un compromiso con cierta objetividad considerada en sentido ontológico en el ámbito del derecho. Esto quiere decir que la existencia del derecho en cuanto objeto es independiente

49 Kramer, Objectivity and the Rule of Law, op. cit., p. 2.

$50 \mathrm{Al}$ respecto, se ha criticado esta disyuntiva indagando acerca de si un gobierno por medio del derecho no es 283 también un gobierno de los hombres, pero por medio del derecho. Celano ha hecho una serie de apreciaciones sobre este punto, algunas de las cuales han sido recogidas en el apartado anterior. 
de ciertos estados mentales de sujetos determinados, que las respuestas que el derecho busca proporcionar a los problemas sociales no están determinadas predominantemente por una voluntad $a d h o c$, y que la formulación de las reglas conforme a las pautas del rule of law tiende a prevenir una aplicación subjetiva de estas.

La primera especie de objetividad ontológica supone que el derecho en cuanto fenómeno no depende de ciertos estados mentales de algún sujeto para existir. La existencia del derecho y sus propiedades relevantes es independiente de que un individuo determinado lo piense. A diferencia de ciertas creencias, fantasías o emociones, las reglas jurídicas generales existen con independencia de que algún individuo particular las piense en un momento determinado. ${ }^{51}$

Este sentido de objetividad se halla presente en la noción de rule of law en cuanto presupone deferencia a reglas preestablecidas. En otras palabras, de las exigencias formales implicadas en el referido ideal, se infiere la necesidad de que el derecho en cuanto tal exista con independencia de lo que ocurra en la mente del legislador o aplicador de las reglas. Por ejemplo, si las reglas han de ser promulgadas para poder ser cumplidas, nunca podrá contar como regla objetiva, en el sentido indicado, una orden que únicamente se halla en la mente de un legislador y que este desea que se cumpla.

La segunda especie de objetividad ontológica tiene que ver con la potencialidad del derecho para brindar respuestas correctas. Para Kramer, el principal modo de socavar la objetividad en este sentido tiene que ver con la indeterminación. Cuando las normas jurídicas son indeterminadas, el rango de posibles respuestas que el derecho puede brindar ante situaciones conflictivas se amplía notablemente..$^{52}$ De tal modo, la indeterminación de las reglas puede dar lugar a múltiples cursos de acción, y los jueces al aplicarlas pueden optar por cualquiera de ellos, sin que esto implique obrar en contra de lo prescrito por el derecho. Sin embargo, esas decisiones, incluso pueden resultar sorpresivas para potenciales sujetos afectados.

51 Kramer, Objectivity and the Rule of Law, op. cit., pp. 6-7. Kramer llama a este sentido de objetividad como débil. El contraste estaría dado por un sentido fuerte que estaría dado por un estado de cosas en el cual ciertas reglas generales fueran ignoradas por todos los miembros de una comunidad política. El autor señala que, entonces, dichas reglas sí serían dependientes del estado mental de esos individuos. De tal modo, la objetividad es conducente solo como independencia de ciertos individuos particulares.

52 Ibid., p. 14. La referencia que el autor hace a la noción de "respuesta correcta" parece inscribirse en la conocida propuesta de Ronald Dworkin frente a los llamados "casos difíciles", que no se halla exenta de problemas. Sin ingresar en ese debate, y a modo de matiz, se ha señalado que, en la solución de los casos judiciales, debe distinguirse entre la corrección de una solución jurídica y su justicia. Lo primero se halla en el campo de lo normativo, y entonces allí sí es posible resolver un caso por medio de diversos cursos de acción correctos, a partir del material jurídico disponible. Lo segundo se encuentra en el ámbito de lo "fronético", es decir, en el campo de la prudencia, y entonces allí sí es posible encontrar una única solución justa en el caso concreto (Carlos Ignacio Massini Correas, Objetividad jurídica e interpretación del derecho, México, Porrúa - U. Panamericana, 2008, pp. 148-151). 
Hacer referencia a la indeterminación de las normas jurídicas supone, al mismo tiempo, considerar la discrecionalidad de la que gozarán los aplicadores del derecho a la hora de hacer efectivas esas normas. Precisamente, este punto sería el que da lugar a cierta creatividad/subjetividad por parte de quienes deben aplicar las reglas preestablecidas. En este caso, la objetividad ya no tiene que ver con la existencia y propiedades de lo que cuenta como derecho, sino con las respuestas que pueden obtenerse del sistema jurídico.

Al respecto se ha dicho que, en realidad, existe una cierta compatibilidad y a la vez una recíproca limitación entre el rule of law y la discrecionalidad jurídica. La compatibilidad supone que el rule of law en cuanto ideal comprende ciertos estándares de excelencia que -a semejanza de los principios jurídicos- requieren satisfacción en la mayor medida posible. Pero, no se trata de satisfacer la certeza del derecho a toda costa. Por ello, en ocasiones, quienes diseñan la legislación dejan abierto cierto margen de indeterminación -además de la indeterminación propia del derecho- para que el aplicador pueda actuar conforme las circunstancias. ${ }^{53}$

En la misma línea, desde una óptica parcialmente diferente, se ha señalado que el rule of law posee tres subideales: la precisión, por la cual el lenguaje del derecho debe ser determinado; la justicia formal, por la que el derecho debe tratar casos iguales del mismo modo; y la equidad, ${ }^{54}$ por la cual el derecho debe acomodar excepciones justificadas a reglas generales. Los tres subideales pueden presentarse de modo excluyente, por ejemplo, cuando en algunas situaciones la precisión conspira contra la justicia formal y trata de manera diferente casos iguales (por ejemplo, cuando una persona mayor de edad recibe un tratamiento, y una persona a la que le falta un día para cumplir la mayoría de edad, recibe otro). O cuando la precisión conspira contra la equidad (por ejemplo, cuando ciertos plazos procesales impiden el acceso a la justicia). Frente a esto se ha señalado que la existencia de "conceptos multidimensionales" como las ideas de razonabilidad, proporcionalidad, buena fe o diligencia permiten el establecimiento de excepciones, actúan como defeaters y reestablecen la equidad. ${ }^{55}$

No obstante, el rule of law busca asegurar una parte limitada de las exigencias de justicia que podrían esperarse de un sistema jurídico-político. Concretamente,

53 Juan Bautista Etcheverry, "Rule of Law y discrecionalidad judicial: compatibilidad y recíproca limitación”, en Revista Derecho del Estado, 36 (2017), pp. 15-16.

54 La introducción de la idea de equidad como subideal del rule of law, no necesariamente se sigue de un esquema formal como el asumido en este trabajo. La derivación de la equidad de un esquema como el del rule of law supone asumir alguna de las posiciones más o menos robustas de este, que supone algún contenido sustantivo, además del implícito en dicho ideal. Es decir, asume que junto a las reglas formales debe haber algún contenido mínimo de justicia. En cambio, para la posición que aquí se ha asumido, el rule of law tiene que ver con exigencias formales, sin asumir exigencias sustantivas explícitas, aunque algún grado de estas se encuentre presupuesto en la guía de la conducta humana por medio de reglas, como se explicó.

55 Juan José Moreso, “La incorporación de la moral en el razonamiento judicial”, en Manuel Vial Dumas y David Martínez Zorrilla (coords.), Pensando al juez, Madrid, Marcial Pons, 2019, pp. 98, 102-103. 
... aquella parte que tiene que ver con la promoción de un tipo especial de coordinación que pueda servir para prevenir y solucionar conflictos de un modo que garantice alguna forma de reciprocidad en la cooperación entre los ciudadanos y la autoridad, que presuponga un respeto por la autonomía humana e imparcialidad en la resolución de conflictos. ${ }^{56}$

Pero hay otros caminos para asegurar exigencias de justicia en el marco del sistema jurídico, y Estos pueden tener que ver en ocasiones con un prudente recurso a la indeterminación del derecho.

Por ello, un indicador importante de que se ha vulnerado el rule of law tiene que ver con la incapacidad de las normas jurídicas como instrumentos para la guía de la conducta. ${ }^{57}$ En otras palabras, y en referencia al sentido de objetividad de que se trata, cuando de las normas jurídicas consideradas no es posible extraer respuestas que permitan cierta previsión de las consecuencias de las propias acciones. En esos casos de falta de certeza/previsibilidad, la solución de la cuestión quedará en manos de un decisor, y solo en sus manos.

El tercer sentido de objetividad ontológica tiene que ver con la aplicación uniforme de las normas jurídicas. La objetividad así entendida se relaciona particularmente con una de las exigencias del rule of law como es la generalidad con que las normas deben formularse. En efecto, desde la óptica de los destinatarios, una norma es general cuando "se dirige a una clase o tipo de destinatarios, y no a un destinatario individualizado" ${ }^{58}$ Esto hace que al momento de aplicarse las normas no se tengan en cuenta condiciones particulares de los sujetos a quienes se les aplicará, sino solo las propiedades genéricas fijadas por la regla. Esta prescindencia de cualidades particulares de los destinatarios hace que la aplicación sea objetiva.

Por otra parte, la objetividad como aplicación uniforme supone una cierta actitud de parte de quien aplicará la norma. Dicha aplicación resultará objetiva cuando el juez no realice una "acepción de personas" al momento de decidir. Es decir, deberá ser imparcial, equidistante y no identificarse con una parte más que con la otra. ${ }^{59}$ Lo contrario implicaría una actitud subjetiva. Es decir, más que las propias normas, el criterio orientador de las decisiones tendría que ver con cierta simpatía o afinidad hacia las partes involucradas, por ejemplo, en un conflicto jurídico.

57 Gregoire Webber, "Rights and the Rule of Law in the balance", en Law Quarterly Review, 129 (2013), p. 403. En este trabajo, el autor trata el problema que apareja el atrincheramiento de derechos a través de los llamados bill of rights, particularmente para poder extraer respuestas correctas de declaraciones que en sí mismas son infradeterminadas.

58 Laporta, El imperio de la ley, op. cit., p. 89.

59 Lawrence Solum, “Virtue jurisprudence. Una teoría de la decisión judicial centrada en las virtudes”, trad. de Juan Bautista Etcheverry y Marina Dandois, en Persona y Derecho, 69 (2013), p. 31. 
El rule of law en cuanto ideal jurídico, político y ético guarda afinidad con cierta idea de objetividad en tanto asegura la existencia independiente del derecho, promueve la determinación de las respuestas jurídicas y garantiza la aplicación uniforme de las reglas. El contraste con esa relación de afinidad está dado por la prevalencia del subjetivismo en el campo jurídico, como oposición al compromiso con la objetividad. Una representación del subjetivismo se da en el modelo de administración de justicia descrito por Weber llamado "justicia de Cadi".

En este modelo

... ante la imposibilidad de acceder a las pautas previas de decisión [...] las partes se veían impulsadas a pasar directamente al terreno de la persuasión [...] estableciendo así, no un momento de razonamiento, sino una puesta en escena teatral de su pretensión [...] para tratar de llevar al ánimo del juez por medios directos de compasión o presión emocional el derecho que le asistía a cada uno. ${ }^{60}$

Frente a este contraste, el compromiso con el rule of law es también compromiso con el gobierno de la razón -rule of reason-y de las razones -rule of reasons-.

\section{Conclusión}

Entendido desde una perspectiva formal, el rule of law se compone de un conjunto de exigencias formales (generalidad, prospectividad, publicidad, estabilidad, claridad, consistencia y posibilidad en el cumplimiento), y exigencias institucionales, tales como el acceso a la justicia y la independencia judicial. Se trata de un ideal jurídico, político y ético. En cuanto ideal jurídico, la satisfacción de las exigencias del rule of law asegura la eficacia del derecho dado que procura la guía de la conducta humana bajo el presupuesto de la inteligibilidad de las prescripciones.

En cuanto ideal político, un sistema adherido al rule of law se encontrará entre las formas no manipulativas de ejercicio del poder público -lo que también incluye a la función judicial en el Estado-. Ello, por cuanto la inteligibilidad de las prescripciones permite el cumplimiento voluntario de las reglas por parte de los ciudadanos. El poder sujeto al rule of law es también racional, porque los destinatarios de las reglas son racionales $\mathrm{y}$, como tal, requiere reglas inteligibles y coherentes. Es, además, no paternalista, en el sentido de que el poder ejercido de ese modo no trata a los ciudadanos como infantes, sino como adultos capaces de deliberar y tomar decisiones.

60 Laporta, El imperio de la ley, op. cit., p. 116. 
En cuanto ideal ético, si bien por tratarse de un ideal formal es compatible con ciertas formas sustantivas de injusticia, posee una dimensión moral en tanto trata a los destinatarios de las reglas como agentes racionales. Ese tratamiento guarda deferencia con la idea de dignidad humana en cuanto asegura la previsibilidad de las prescripciones. Asimismo, contribuye a la idea de libertad, entendida como no interferencia.

Las repercusiones normativas de este ideal pueden compendiarse en tres. En primer lugar, la adhesión al rule of law genera cierta eficiencia decisoria. El recurso a las reglas como vehículo de las decisiones públicas hace que no sea necesario efectuar un balance de razones a la hora de tomar partido por cierto curso de acción; de este modo, dichas reglas tienden a resolver problemas de coordinación y cumplen un rol determinativo respecto de ciertos principios morales. A la vez, contribuyen a limitar sesgos cognitivos o emotivos respecto de quien debe tomar decisiones concretas.

En segundo lugar, la distribución y el control del poder decisorio es otra de las consecuencias del rule of law. Dicho ideal presupone un diseño del poder decisorio en el que clases de decisiones se atribuyen a clases de decisores. De este modo, aquel diseño sustrae la decisión sobre la selección de propiedades relevantes contenidas en la regla a la jurisdicción, y sustrae la función de aplicación de la regla a quienes legislan. De tal manera, tiende a minimizar los riesgos de arbitrariedad y hace controlable la actividad de unos y otros decisores. En tercer lugar, la noción de previsibilidad es otra consecuencia del aludido ideal. Esta noción se halla conectada con la idea de autonomía personal. El rule of law se erige en condición necesaria de ella por cuanto previene dos de las posibles lesiones a la autonomía, que son la incertidumbre y la generación de falsas expectativas. Un sistema basado en reglas que respetan las exigencias formales del rule of law permite prever las consecuencias de las normas, porque las mismas normas son previsibles y porque los sujetos destinatarios pueden tener cierta certeza de que los otros sujetos con quienes interactúan conocen el derecho y sus consecuencias.

El compromiso con el ideal de rule of law supone un compromiso con cierta objetividad considerada en sentido ontológico en el ámbito del derecho. Esto quiere decir que la existencia del derecho en cuanto objeto es independiente de ciertos estados mentales de sujetos determinados, que las respuestas que el derecho busca proporcionar a los problemas sociales no están determinadas predominantemente por una voluntad $a d h o c$, y que la formulación de las reglas conforme a las pautas del rule of law tiende a prevenir una aplicación subjetiva de las mismas. 


\section{Bibliografía}

Celano, Bruno, "Law as power. Two Rule of Law requirements", en Wil Waluchow y Stefan Sciaraffa (eds.), Philosophical Foundations of the Nature of Law, Oxford, Oxford University Press, 2013, pp. 121-147.

Celano, Bruno, "Publicity and the Rule of Law", en Leslie Green y Brian Leiter (eds.), Oxford Studies in Philosophy of Law, vol. 2, Oxford, Oxford University Press, 2013, pp. 121-147. https://doi.org/10.1093/acprof:o so/9780199679829.001.0001

Celano, Bruno, "Rule of Law y particularismo ético", en Pau Luque (ed.), Particularismo. Ensayos de filosofía del derecho y filosofía moral, Madrid, Marcial Pons, 2015, pp. 151-186.

Cianciardo, Juan, "Derechos humanos", en Claudia Vanney et al. (eds.), Diccionario Interdisciplinar Austral (2018), en http://dia.austral.edu.ar/Derechos_humanos

Craig, Paul, "Formal and substantive conceptions of the Rule of Law: An analytical framework", en Public Law, 3 (1997), pp. 467-487. https://doi. org/10.4324/9781315085302-4

Etcheverry, Juan Bautista, "La relevancia del derecho que remite a la moral", Problema. Anuario de filosofía y teoría del derecho, 4 (2010), pp. 205-242. http:// dx.doi.org/10.22201/iij.24487937e.2010.4.8093

Etcheverry, Juan Bautista, "Rule of Law y discrecionalidad judicial: compatibilidad y recíproca limitación", en Revista Derecho del Estado, 36 (2017), pp. 3-21. https://doi.org/10.18601/01229893.n38.01

Finnis, John, “Law as co-ordination”, Ratio Juris, 1 (1989), pp. 97-104. https:// doi.org/10.1111/j.1467-9337.1989.tb00029.x

Finnis, John, Ley natural y derechos naturales, Buenos Aires, Abeledo Perrot, trad. de Cristóbal Orrego, 2000.

Fuller, Lon, La moral del derecho, México, Trillas, trad. de Francisco Navarro, 1967.

Gometz, Gianmarco, La certeza jurídica como previsibilidad, Madrid, Marcial Pons, trad. de Diego Moreno Cruz y Diego Dei Vecchi, 2012.

Kramer, Matthew, Objectivity and the Rule of Law, Cambridge, Cambridge University Press, 2007.

Laporta, Francisco, El imperio de la ley, Madrid, Trotta, 2007.

Luzzati, Claudio, L'interprete e il legislatore. Saggio sulla certezza del diritto, Milán, Giuffrè, 1999. 
Massini Correas, Carlos Ignacio, Objetividad jurídica e interpretación del derecho, México, Porrúa y U. Panamericana, 2008.

Moreso, Juan José, "La incorporación de la moral en el razonamiento judicial”, en Manuel Vial Dumas y David Martínez Zorrilla (coords.), Pensando al juez, Madrid, Marcial Pons, 2019, pp. 95-112.

Nozick, Robert, Anarchy, State and Utopia, New York, Basic Books, 1974.

Raz, Joseph, La autoridad del derecho, México, UNAM, trad. de Rolando Tamayo, 1985.

Rivas, Pedro, "Política, poder y derecho. La noción hobbesiana de soberanía en la encrucijada de sentido de lo jurídico y lo político", en Anuario Filosófico, 51, 1 (2018), pp. 11-33. https://doi.org/10.15581/009.51.1.11-33

Simmonds, Nigel, "Law as a moral idea", University of Toronto Law Journal, 55 (2005), pp. 98-131, en https://www.jstor.org/stable/4491638

Solum, Lawrence, “Virtue jurisprudence. Una teoría de la decisión judicial centrada en las virtudes", trad. de Juan Bautista Etcheverry y Marina Dandois, Persona y Derecho, 69 (2013), pp. 5-51, en https://revistas.unav.edu/ index.php/persona-y-derecho/article/view/1571

Summers, Robert, "The principles of the Rule of Law”, Notre Dame Law Review, 74 (1999), pp. 1691-1712, en https://scholarship.law.nd.edu/cgi/viewcontent.cgi? article $=1653 \&$ context $=$ ndlr

Tamanaha, Brian, On the Rule of Law. History, Politics, Theory, Cambridge, Cambridge University Press, 2004.

Webber, Gregoire, "Rights and the Rule of Law in the balance", Law Quarterly Review, 129 (2013), pp. 399-419, en https://ssrn.com/abstract=2488076

\section{Jurisprudencia citada}

Corte Interamericana de Derechos Humanos, López Mendoza vs. Venezuela, Sentencia de 1 de septiembre de 2011, en http://www.corteidh.or.cr/CF/ jurisprudencia2/ficha_tecnica.cfm?nId_Ficha=354 